договора о подключении по индивидуальному проекту. Юридические лица, владеющие сетями, но не оказывающие услуг, связанных с подачей газа, не вправе препятствовать подключению (технологическому присоединению) к принадлежащим им сетям газораспределения и (или) газопотребления при наличии пропускной способности таких сетей.

Датой заключения договора подключения считается дата поступления исполнителю подписанного со стороны заявителя договора в письменной форме, а случае заключения договора через личный кабинет то момент подписания цифровой подписью.

Существенными условиями договора подключения помимо мероприятий, выполняемых сторонами являются: сроки подключения, разграничение имущественной ответственности, порядок и размер внесения платы за подключение (искл. - догазификация), стоимость проекта и экспертизы (для индивидуальных проектов), ответственность сторон и неустойка за просрочку исполнения обязательств, технические условия, право заявителя на односторонний отказ от исполнения договора, обязанность для исполнителя исполнить договор в т.ч. когда необходимо строительство на земельных участках третьих лиц включая обращение в адрес уполномоченных государственных органов за установлением публичного сервитута, мониторинг исполнения технических условий.

Сроки подключения устанавливаются Правилами в зависимости от категории заявителя: не более 135 дней для заявителей 1 категории (часовой расход не более 42 куб.м., а расстояние от участка до газораспределительной сети не более 200м); 1,5 года для заявителей 2 категории ( не более 500м для территории вне населённых пунктов и не более 300 м в населённых пунктах); 2 года для заявителей 3 категории (соответственно протяжённость превышает указанные показатели либо система газораспределения затрагивает сразу два или более муниципальных образований). Правилами также в конкретных календарных показателях установлены основания и сроки продления мероприятий по подключению [3].

Детальная регламентация Правилами подключения всех процедур, возникающих в процессе выполнения мероприятий по технологическому присоединению направлена прежде всего на защиту интересов заявителей, вносит временную определённость и содействует вовлечению максимально большого количества заявителей в процессы газификации.

$$
* * *
$$

1. Федеральный закон от 31.03.1999 N 69-Ф3 «О газоснабжении в Российской Федерации» // СПС КонсультантПлюс;

2. Казаченок О.П. Цифровые права в современном гражданском обороте: тенденции и перспективы развития// Хозяйство и право. 2019, №11, ст.39-44;

3. Постановление Правительства РФ от 13.09.2021 N 1547 «Об утверждении Правил подключения (технологического присоединения) газоиспользующего оборудования и объектов капитального строительства к сетям газораспределения» // СПС КонсультантПлюс.

\title{
Пузиков С.А. \\ О некоторых особенностях развития инноваций в условиях конкуренции и антимонопольного регулирования
}

Волгоградский государственньй университет (Россия, Волгоград)

doi: 10.18411/trnio-01-2022-194

Научньй руководитель: Копьев А.В.

\author{
Аннотация \\ В статье кратко рассмотрены отдельные проблемные вопросы, связанные с развитием \\ инноваций в условиях конкуренции.
}

Ключевые слова: инновация, антимонопольная служба, конкуренция. 


\section{Abstract}

The article briefly discusses certain problematic issues related to the development of innovations in a competitive environment.

Keywords: innovation, antitrust service, competition.

По мнению отдельных авторов, в настоящее время, в связи с происходящими в стране процессами в социуме и экономике, объективно сложилась ситуация требующая обновлённого правого регулирования, в частности, в области развития информационных технологий, которые относятся в полной мере к инновациям в этой области.

Развитие информационного общества на современном этапе характеризуется структурными изменениями многих экономических и социальных процессов, требующих обновлённого правового регулирования, вышеуказанное мнение относится и к понятию инноваций.

Инновации слишком долго были парадоксом антимонопольного законодательства. Специалисты в области антимонопольного законодательства и правоохранительные органы согласны с тем, что инновации жизненно важны для обеспечения соблюдения антимонопольного законодательства. Различные школы считают инновации главной целью конкуренции. Тем не менее, несмотря на общепризнанную важность, инновации остаются недостающим принципом антимонопольного законодательства. Редко инновации воспринимаются как главный источник конкуренции. В основе этих важнейших отношений лежит динамический подход к конкуренции. Инновационные модели могут не иметь отношения к рыночным структурам.

Антимонопольные дебаты в юридической и экономической литературе исторически относились к инновациям с некоторым пренебрежением или, по крайней мере, с пренебрежением. Действительно, инновации оставались вспомогательной темой в антимонопольном сообществе, которое в целом соглашается с важностью инноваций для конкуренции, но при этом регулярно принижает роль инноваций в антимонопольном анализе как всего лишь вспомогательный параметр.

Таким образом, антимонопольные дебаты принимают во внимание инновации только для «рынков высоких технологий», «рынков киберпространства» или «рынков технологий». Чтобы провести различие между этими инновационными рынками и неинновационными рынками, необходимо провести разделительную линию. Это предполагает, что неинновационные рынки не подвержены и не могут подвергаться ураганам созидательного разрушения из-за новых бизнес-моделей, продуктов или услуг, основанных на новых технологиях. Но эти рынки часто одинаково противостоят этим разрушительным и неизбежным штормам.

Таким образом, случайное, а не систематическое упоминание инноваций ограничивает создание основанного на инновациях антимонопольного законодательства. Инновации больше не должны оставаться парадоксом, они должны стать краеугольным камнем теории и практики конкурентной политики.

Конкуренция фирм - неотъемлемая часть экономической эволюции, представляющая собой естественный процесс конкуренции компаний за ограниченные ресурсы. Этот процесс включает в себя эволюционный поиск, накопление информации и последующее превращение этой информации в рыночные и стратегические знания - другими словами, в инновации.

Антимонопольные органы должны сосредоточить свое внимание не только на преимуществах инноваций, получаемых от фирм, обладающих хотя бы некоторой рыночной властью, но и на угрозах рыночной власти, которые создают подрывные инновации, в том числе со стороны новых участников.

Благодаря инновациям предприниматель и, в большей степени, корпорация могут получить стратегическое преимущество - таким образом, получить доступ к ограниченным ресурсам (например, инвестиционным активам или новой клиентской базе) с большей 
скоростью, чем у их конкурентов. Фирмы используют возможности, которые позволяют им использовать возможности и вводить новшества. Затем, через последующий маркетинг этих возможностей, фирмы вводят новшества на рынке. В большинстве отраслей только за счет инноваций фирмы могут значительно превзойти своих конкурентов.

Успешные фирмы часто обладают преходящей рыночной властью до тех пор, пока последующие инновации конкурентов не подорвут их собственный статус подрывного новатора. Чем больше рыночное положение фирмы позволяет присвоить ценность, полученную от инноваций, тем больше его потенциальные участники будут заинтересованы в том, чтобы сами получить эти рыночные возможности за счет инноваций.

Технологический прогресс и сбой на рынке стимулируют эффективную и агрессивную конкуренцию, приносящую пользу как потребителям, так и инновациям в целом. В этом эволюционном процессе инновации создают условия для конкуренции.

Конкуренция, в свою очередь, создает основу для дальнейших инноваций. «Инновация как конкуренция» объясняет эволюционный процесс открытий для участников рынка в этом конкурирующем процессе. Конкуренция обычно воспринимается как источник инноваций. Попав в конкурентную среду, предприниматели обязаны вводить новшества, чтобы «избежать» давления со стороны конкурентов. Эти конкурентные ограничения снижают прибыльность фирм. Следовательно, постоянная конкуренция не позволяет фирмам расти и достигать необходимого масштаба, если предприниматели не вводят новшества. Это инновация, основанная на принципах «конкуренции-бегства», в которой инновации представляют собой необходимый выход из агрессивной конкуренции.

Однако это поэтапное нововведение, направленное на то, чтобы «избежать» конкуренции, не в полной мере отражает наиболее важный аспект шумпетерианской конкуренции: конкуренцию, которая не происходит «на полях». Вместо этого Шумпетер описал конкуренцию, которая подрывает устоявшиеся компании и бизнес-модели благодаря инновациям.

Прекрасный пример такой динамики можно увидеть в индустрии телефонных услуг. Политики США давно стремились повысить конкуренцию в сфере телефонии. После первоначального изменения правил, позволяющих компаниям дальней связи, таким как МCI и Sprint, выходить на рынок, они приняли Закон о телекоммуникациях 1996 года, который заставил открыть местные рынки для других телефонных компаний. Мало того, что эта регламентированная конкуренция провалилась (например, обвал конкурентного местного биржевого рынка в начале 2000-х годов), но и развитие сотовой и интернет-телефонии (а в последнее время, видео-чата и приложений для обмена сообщениями) нарушило сеть, переключился на телефонный бизнес и создал острую конкуренцию. Действительно, сбои самый важный источник конкуренции. Динамические возможности фирм позволяют им вести разрушительную конкуренцию.

Примечательно, что, поскольку политика в области конкуренции традиционно рассматривала конкуренцию как фактор, определяющий инновации, альтернативные и наиболее фундаментальные причинно-следственные связи обычно остаются незамеченными. Эта взаимосвязь между конкуренцией и инновациями учитывает и эмпирически демонстрирует, что инновации являются следствием конкуренции и, что более важно, двигателем конкуренции.

Динамическая перспектива антимонопольного правоприменения защитит динамические возможности фирмы и стимулы предпринимателя для создания и получения соответствующих инновационных выгод.

Динамичный взгляд на конкуренцию будет преследовать инновации как явную цель и сохранить их как фундаментальную предпосылку для конкуренции. Действительно, инновации - это палка о двух концах по отношению к конкуренции: инновации вытекают из конкуренции, а также из нее следует. Потребительские выгоды соответствуют относительно 
более среднесрочной цели, а именно, менее пяти лет. Инновации соответствуют долгосрочным перспективам, а именно пяти годам и более. Инновации как цель обеспечения соблюдения антимонопольного законодательства обеспечивают сохранение инновационных стимулов, поэтому процесс созидательного разрушения стимулируется, а не сдерживается.

Динамичное исполнение антимонопольного законодательства в первую очередь гарантирует, что исполнение не принесет потребителю больше вреда, чем пользы в краткосрочной перспективе. Таким образом, доказательства того, что антиконкурентная практика причиняет вред потребителю, является необходимым, хотя и недостаточным, спусковым крючком для антимонопольного анализа, проводимого агентствами с определенным поведением.

Антимонопольное законодательство, основанное на инновациях, означает, что инновации должны быть неотъемлемой частью антимонопольного анализа, проводимого органами антимонопольного права и, в конечном итоге, проверяться в судах. Антимонопольное законодательство, основанное на инновациях, делает инновации первостепенной задачей антимонопольного обеспечения.

Ничто более мощное, чем инновации, не может обеспечить прогресс. Наша жизнь и общество существенно улучшились за последние 100 лет благодаря инновациям: реактивные авиалинии, биофармацевтика, электронная связь, автоматизация и многое другое. Именно инновации заставляют общество двигаться вперед по траектории прогресса - и именно прогресс эффективно решает социальные проблемы. Более того, изменения в инновациях заставляют людей проявлять открытость, терпимость и приспособляемость, составляя движущую силу успеха общества. Таким образом, социальные изменения, вызванные инновациями, представляют собой огромные кратчайшие пути к повышению благосостояния людей.

Нет ничего более мощного, чем инновации, которые могут принести экономические выгоды. Инновации обеспечивают примерно 80 процентов роста доходов на душу населения в развитых странах. Ураганы созидательного разрушения открывают несоизмеримые экономические выгоды, когда покупательная способность домашних хозяйств повышается когда недоступные по цене предметы становятся доступными или даже бесплатными. Инновации позволяют людям улучшать свои экономические условия, делая основные потребности более доступными, тем самым открывая мир возможностей. Семьдесят пять лет назад, например, кондиционирование воздуха было роскошью; сегодня это необходимость.

Большинство инноваций - это социальные инновации, потому что общество, перефразируя Шумпетера, нарушено не на периферии, а на самой его природе.

Следовательно, антимонопольное законодательство должно преследовать социальные инновации в качестве своей основной цели. В противном случае рост благосостояния прекратится и перемены остановятся. Но и процветание, и социальные изменения лежат в основе успеха любого капиталистического общества.

Инновации представляют собой экономический императив для сокращения масштабов нищеты, экономического благосостояния людей и открываемых ими предпринимательских возможностей. Нельзя сбрасывать со счетов инновации как наиболее эффективный двигатель процветания.

Антимонопольное законодательство должно выйти за рамки статической конкуренции и поддержать динамичную конкуренцию. Антимонопольные органы больше не могут игнорировать то, что инновации являются источником конкуренции, а не просто неожиданным и недооцененным результатом конкуренции. Следовательно, антимонопольное правоприменение и институциональные принципы должны быть пересмотрены на основе более реалистичной и менее формализованной модели. 
Таким образом, динамическое антимонопольное законодательство должно избегать подавления инноваций и обеспечивать, чтобы антимонопольные вмешательства имели место только тогда, когда стимулы к инновациям неоправданно искажаются.

$$
* * *
$$

1. Казаченок О.П. Несоответствие действующего законодательства потребностям информационного общества на примере займа электронных денежных средств//аконы России: опыт, анализ, практика. 2017 № 10. С. 4750 ;

2. Шумпетер, Й. Теория экономического развития / И. Шумпетер; пер. с нем. - М.: Прогресс, 2017. - 455 с;

3. Principles of Dynamic Antitrust: Competing Through Innovation [Электронный ресурс]. - Режим доступа: https://itif.org/publications/2021/06/14/principles-dynamic-antitrust-competing-through-innovation (дата обращения: 05.12.2021)

\section{Радоняк В.P. Проблематика аудиторской деятельности \\ Кубанский государственный аграрный университет им. И. Т. Трубилина (Россия, Краснодар)}

doi: 10.18411/trnio-01-2022-195

\section{Аннотация}

Автором анализируются основные проблемные зоны аудиторской деятельности. Перечислены задачи практики аудита как социального института и формы финансового контроля в современной России. Приведены основные причины низкого уровня спроса на аудиторские услуги. Упомянуты приемы и методы, используемые аудиторами, обеспечивающие систематическое и всестороннее изучение показателей финансовохозяйственной деятельности организации и ее структурных подразделений. Автор сформулировал и обосновал вывод о том, что становление аудита как социального института и формы финансового контроля в современной России можно назвать сложным последовательным процессом. В свою очередь, на текущем этапе развития, объединив национальную практику и международный опыт регулирования аудита, аудит перешел на новый уровень регулирования. В качестве выводов автором сформулированы рекомендации по решению вышеперечисленных проблем.

Ключевые слова: право, финансовое право, аудит, аудиторская деятельность, внутренний контроль, аудитор.

\section{Abstract}

The author analyzes the main problem areas of auditing. The tasks of audit practice as a social institution and a form of financial control in modern Russia are listed. The main reasons for the low level of demand for audit services are given. The techniques and methods used by auditors, which provide a systematic and comprehensive study of the indicators of the financial and economic activities of an organization and its structural divisions, are mentioned. The author formulated and substantiated the conclusion that the formation of audit as a social institution and a form of financial control in modern Russia can be called a complex sequential process. In turn, at the current stage of development, by combining national practice and international experience in audit regulation, audit has moved to a new level of regulation. As conclusions, the author formulated recommendations for solving the above problems.

Keywords: law, financial law, audit, audit activity, internal control, auditor.

Практика функционирования хозяйствующих субъектов с течением времени порождает необходимость проведения аудита основных средств - комплексной проверки, вопервых, законности проведенных операций, определяющих процессы их движения, во- 